\title{
HERBERT MARCUSE - ANTICAPITALISMO E EMANCIPAÇÃO ${ }^{12}$
}

\author{
Isabel LOUREIRO ${ }^{3}$ \\ Um intelectual é alguém que se recusa a \\ fazer compromissos com os dominantes. \\ Herbert Marcuse
}

- RESUMO: Marcuse teve no Brasil na década de 1970 uma recepção unilateral, sendo visto unicamente como guru da contra-cultura. Contra esse equívoco o artigo mostra a relação intrínseca entre teoria e prática na filosofia de Marcuse, caracterizada como uma filosofia política cuja preocupação central é a transformação radical da sociedade capitalista.

- PALAVRAS-CHAVE: Herbert Marcuse; Teoria Crítica; civilização ocidental; revolução.

Marcuse teve no Brasil uma péssima recepção. Nas décadas de 1960/ 1970, época de seu grande sucesso junto aos estudantes rebeldes, acabou sendo identificado unilateralmente com a contra-cultura, o que gerou incompreensões por todos os lados. As escolas católicas, vendo nele um arauto da permissividade sexual e da liberação das drogas, proibiam a leitura de suas obras. A esquerda comunista interpretava sua crítica à cultura ociden-

1 Artigo recebido em 05/2005; aprovado para publicação em 09/2005.

2 Originalmente as idéias expostas e publicadas agora com ligeiras modificações foram apresentadas na FCL, UNESP, campus de Araraquara, em dezembro de 2000.

3 Professora aposentada do Departamento de Filosofia, FFC, UNESP, campus de Marília; belloureiro $@$ uol.com.br 
tal como irracionalista. ${ }^{4} \mathrm{E}$ a academia, exclusivamente voltada na época para a exigente tarefa da leitura estrutural dos textos filosóficos não tinha tempo para se entreter com um filósofo que, no seu entender, padecia de falta de rigor. ${ }^{5}$

Talvez uma das razões dessa incompreensão decorra da má divulgação de sua obra. Eros e civilização (1955) e Ideologia da sociedade industrial (1964), livros que tornaram Marcuse conhecido no mundo inteiro, foram publicados no Brasil nos anos 60. Mais tarde apareceu Razão e revolução (Paz e Terra, 1978), escrito em 1941. Mas os ensaios dos anos 30, que originalmente faziam parte da Revista de Pesquisa Social e que mostram claramente a contribuição fundamental de Marcuse à elaboração da Teoria Crítica da sociedade, só recentemente foram traduzidos no Brasil. ${ }^{6}$ Convém registrar que o volume da coleção Os Pensadores dedicado à Escola de Frankfurt reuniu ensaios de Benjamin, Adorno, Horkheimer e Habermas e excluiu Marcuse, o que não deixa de ser revelador da incompreensão acima mencionada. Mas talvez a razão mais profunda de tal descaso aparentemente incompreensível esteja em outro lugar. É o que tentarei mostrar brevemente neste texto.

Desde o início de sua carreira filosófica Marcuse teve uma preocupação central: construir uma filosofia política voltada para a emancipação humana, ou seja, longe da filosofia acadêmica, ${ }^{7}$ unicamente entregue a seus próprios problemas internos e longe da força das coisas. Numa entrevista

4 Ver Carlos Nelson Coutinho, Dois momentos brasileiros da Escola de Frankfurt. In: Cultura e sociedade no Brasil. Ensaios sobre idéias e formas. Belo Horizonte: Oficina de Livros, 1990.

5 Paulo Arantes, em depoimento à Folha de S. Paulo (Mais!, 10.05.1998) sobre a rebelião estudantil de maio de 68, diz: "Era moda aliás nos altos escalões do saber mariantonesco desancar o pobre Marcuse - por falta de rigor, é claro. Grande Recusa não era mesmo conosco".

6 Ver introdução de Wolfgang Leo Maar em Herbert Marcuse, Cultura e sociedade, vol. 1, São Paulo, Paz e Terra, 1997. Ver também Cultura e sociedade, vol. 2, São Paulo, Paz e Terra, 1998. Quero deixar registrado o quanto Marcuse foi mal traduzido no Brasil, nos anos 1960/70, nas edições publicadas pela Zahar. Eros e civilização apresenta problemas sérios, mas sobretudo O homem unidimensional (traduzido por Ideologia da sociedade industrial) tem erros grosseiros, como por exemplo, verter "reification" por "espoliação", além de passagens totalmente incompreensíveis. Isso para não falar do verdadeiro samba do crioulo doido que é a tradução feita por Vamireh Chacon de um ensaio de Marcuse de 1928 (Contribuições para uma fenomenologia do materialismo histórico, traduzido por Contribuições para a compreensão de uma Fenomenologia do Materialismo histórico, in Materialismo histórico e existência, Rio de Janeiro, Tempo Brasileiro, 1968), que chega a ser ilegível de tão confusa. Também Idéias para uma Teoria Crítica da sociedade (aqui traduzido como Idéias sobre (sic!) uma Teoria Crítica da sociedade, Rio de Janeiro, Zahar, 1981) tem erros que comprometem o texto, tornando um suplício a leitura de um autor que prima pela clareza e elegância do estilo.

7 Embora, evidentemente, dominasse os instrumentos para tal, como comprovam tanto a tese de doutorado (Der deutsche Künstlerroman, 1922) quanto a tese de habilitação (Hegels Ontologie und die Theorie der Geschichtlichkeit, 1932). Sobre o desenvolvimento filosófico-político de Mar- 
ao final da vida, interrogado a respeito de por que escolhera essa carreira, Marcuse responde que queria ser "(...) filósofo num sentido hoje quase inconcebível, quer dizer, alguém que com base no que aprendeu e na sua experiência possa realmente entender, descobrir e transformar a realidade em que vive. Uma definição consideravelmente política da filosofia, que contudo remonta a ninguém menos que Platão." 8

Marcuse de fato foi o único filósofo da Escola de Frankfurt que, mesmo sem ter militância política em sentido estrito, ${ }^{9}$ sempre permaneceu um teórico da revolução. Desde o início sua obra gira em torno de um problema: a necessidade da transformação radical da sociedade capitalista. Foi a derrota da revolução alemã que o sensibilizou para a política, como ele mesmo reconhece em várias entrevistas dadas ao longo da vida. Marcuse tem uma necessidade premente de entender por que uma revolução, que parecia na ordem do dia, acaba derrotada e as antigas classes dominantes retornam, fortalecidas. Com esse objetivo, começa a ler Marx. Mas um Marx filtrado pelo Lukács de História e consciência de classe e o Korsch de Marxismo e filosofia, livros críticos do marxismo economicista dos partidos operários oficiais.

Se perguntássemos a Marcuse qual o texto que fez sua cabeça ele responderia sem titubear: os Manuscritos Econômico-Filosóficos do jovem Marx, que, publicados em 1932, receberam de sua parte um comentário detalhado, e cujas idéias o acompanharam durante a vida inteira. O comunismo a que Marx se referia nos Manuscritos não significava apenas a transformação radical das bases materiais da sociedade, mas também a emancipação completa do ser humano, o que, na interpretação de Marcuse, representava a emancipação dos sentidos e a transformação radical da consciência e do inconsciente. Em outras palavras, para Marcuse os Manuscritos anunciavam em termos políticos o que mais tarde Freud viria a fazer em termos psicológicos. E foi exatamente para a dimensão da subjetividade, negligenciada pelo marxismo dos partidos políticos, que Marcuse se voltou depois da Segunda Guerra Mundial, pois via na situação daquela época uma repetição da história: novamente a revolução havia sido derro-

cuse, ver Isabel Loureiro, Herbert Marcuse - a relação entre teoria e prática, in Loureiro, I., Musse, R., (org.) Capítulos do marxismo ocidental, São Paulo, Editora UNESP/FAPESP, 1998.

8 Herbert Marcuse, A grande recusa hoje, Petrópolis, Vozes, 1999, Coleção Zero à Esquerda, p.1112. Doravante, GR.

9 A não ser em alguns períodos da vida: quando jovem foi, por um curto período, membro de um conselho de soldados em Berlim, no início da revolução alemã; na maturidade, participou do esforço de guerra contra o nazismo, trabalhando como analista político para o governo americano em Washington; e na velhice, suas idéias o aproximaram da nova esquerda e do movimento estudantil, cujas insuficiências e debilidades, porém, nunca deixou de apontar. 
tada, nos EUA explodiram o macartismo e a guerra fria, e a URSS por seu lado não representava nenhuma alternativa emancipadora. Nesse contexto, Marcuse passou a estudar Freud sistematicamente, pois sem sabermos como funciona a subjetividade humana a luta política seria ineficaz. Foi a partir daí que compreendeu que sem uma transformação radical da consciência e do inconsciente, das necessidades e aspirações humanas as revoluções estariam para sempre votadas ao fracasso. Aqui se juntavam o jovem Marx e a psicanálise freudiana, tal como ele a interpretou. Em resumo, Marcuse procura renovar o marxismo, e alarga o campo de suas preocupações ao teorizar sobre a dimensão subjetiva da vida humana vinculada à mudança social.

Nesse sentido, podemos dizer que diferentemente de Adorno e Horkheimer, que a partir dos anos 40 se dedicaram à crítica da cultura desvinculada da política radical, Marcuse levou adiante o projeto da Teoria Crítica dos anos 30 - unir filosofia, teoria social e política revolucionária. A preocupação política é muito clara, por exemplo, nos textos dos anos 1940 produzidos na época em que trabalhava para o governo americano ${ }^{10}$ o que leva a relativizar a interpretação corriqueira sobre a Teoria Crítica dos anos 40, segundo a qual esta teria ficado resignada à contemplação, abandonando a unidade entre teoria e prática. No caso de Marcuse esta interpretação não se sustenta ${ }^{11}$ pois justamente a procura de vínculo com a prática é o fio condutor do seu pensamento.

Procurarei apresentar essa idéia expondo em grandes traços qual é sua análise do capitalismo tardio ("sociedade industrial avançada", na sua terminologia) e o que seria no seu entender uma sociedade emancipada, ou seja, socialista. Para isso vou me deter basicamente em Eros e Civilização, e lembrar, sempre que necessário, passagens dos artigos e entrevistas pu-

10 Ver Herbert Marcuse, Tecnologia, guerra e fascismo, São Paulo, Editora UNESP, 1999.

11 Para Marcuse, a busca de unidade entre teoria e prática gera, no plano individual, uma exigência moral de coerência entre o pessoal e o político, duas esferas que entende como inseparáveis. É o que vemos, por exemplo, na correspondência com Heidegger (1947-48), quando ele exige de seu antigo professor uma retratação (que Heidegger se recusa a fazer) em virtude de seu apoio ao nazismo. Escreve Marcuse: "Eu - e muitíssimos outros - o admiramos como filósofo e aprendemos muitíssimo com o senhor. Mas não podemos separar Heidegger o filósofo e Heidegger o homem essa separação contradiz sua própria filosofia" (GR, p.42). Nesse momento Marcuse tem dificuldade de aceitar a idéia de que em Ser e Tempo, obra que tanto admirava e que tanto o havia influenciado, já se anunciava de alguma forma a possibilidade de adesão ao nazismo. Mais tarde reconhece, numa entrevista de 1977: "Vejo agora nessa filosofia, ex-post, uma fortíssima desvalorização da vida, uma depreciação da alegria, da sensibilidade, da satisfação. Devemos ter sentido isso na época mas só ficou claro depois que a associação de Heidegger com o nazismo se tornou conhecida." (Heidegger's Politics: an Interview with Herbert Marcuse by Frederick Olafson, Graduate Faculty Philosophy Journal, vol. 6, n 1, Winter, 1977, p.33). 
blicados em A Grande Recusa hoje, que retomam de maneira explícita idéias que começaram a germinar nos anos 1950.

A grande preocupação de Marcuse a partir do pós-guerra é com uma teoria do sujeito (um novo sujeito histórico, pois o velho sujeito revolucionário, a classe trabalhadora, estava integrada à sociedade de consumo). Para elaborar essa teoria, volta-se para a psicanálise de Freud. Ele quer entender por que "todas as revoluções foram também revoluções traídas". ${ }^{12}$ Para isso não basta uma análise em termos econômico-políticos. É preciso ir além, entender por que, junto com o Termidor histórico-social, vem o "Termidor psíquico": os rebeldes, ao derrubarem o velho poder, se identificam com ele e por isso tornam a instituir um novo poder tão ou mais opressivo que o anterior. Ou seja, a dominação é interiorizada, o que explica as sucessivas derrotas em termos psicológicos. Marcuse se pergunta se não haveria já nos próprios indivíduos "uma dinâmica que nega internamente a libertação e a satisfação possíveis fazendo que os indivíduos se dobrem à negação não apenas do exterior?"13 É esse indivíduo auto-reprimido que apóia os senhores e suas instituições. Assim sendo, é preciso entender a derrota das revoluções em termos econômicos, políticos, sociais, históricos e psicológicos. É a repressão das pulsões de vida (Eros) que cria indivíduos aptos a aceitarem uma sociedade repressiva e a temerem sua própria libertação. Na conferência "Ecologia e crítica da sociedade moderna" (1977), diz Marcuse:

Os indivíduos introjetam valores e objetivos, os quais estão incorporados nas instituições sociais, na divisão social do trabalho, na estrutura de poder estabelecida, e assim por diante. E, inversamente, as instituições sociais e políticas refletem (...) as necessidades socializadas dos indivíduos, as quais se tornam deste modo suas próprias necessidades.

Este é um dos processos mais importantes na sociedade contemporânea. Com efeito, as necessidades que verdadeiramente são oferecidas aos indivíduos pelas instituições, e em muitos casos impostas aos indivíduos, acabam tornando-se as

12 Numa entrevista de janeiro de 1971 à televisão da Baviera, ele assim explicou essa idéia: "Nessa época [começo dos anos 30] fui me tornando cada vez mais político. Era claro que o fascismo viria e isso me levou a um estudo intensivo de Marx e Hegel. Freud veio um pouco mais tarde. Tudo isso com o propósito de entender por que numa época em que realmente estavam dadas as condições para uma revolução autêntica, essa revolução fracassou ou foi derrotada, as antigas forças voltam ao poder e tudo recomeçou numa forma ainda pior."(Revolution oder Reform?, Munique, Kösel-Verlag, 1976, p.4).

13 A noção de progresso à luz da psicanálise (1968). In: Marcuse, H. Cultura e psicanálise. São Paulo: Paz e Terra, 2001, p.131. 
próprias necessidades e carências dos indivíduos. Esta aceitação das necessidades impostas contribui para uma estrutura de caráter afirmativo. (GR, p.146-47)

Como seria possível então na sociedade industrial avançada fazer explodir essa estrutura de caráter que apóia os senhores e suas instituições? Como seria possível uma "subjetividade rebelde"? Marcuse acredita existir a possibilidade objetiva do que Bloch denominou "utopia concreta". "Utopia", porque essa sociedade não existe em lugar algum; "concreta" porque é uma possibilidade histórica real (GR, p.148). O problema seria a inexistência de um sujeito histórico "eficaz" para viabilizar essa utopia que ele vê como possível. Qual é o seu argumento?

No capitalismo avançado, com a automação do trabalho não é mais necessário reprimir os indivíduos para que trabalhem, tal como era preciso numa sociedade de escassez. Essa era a hipótese de Freud sobre a qual se assentava a idéia de que a civilização exige a repressão das pulsões, exige que o "princípio de prazer" se subordine ao "princípio de realidade". Fazendo uma leitura marxista de Freud, Marcuse cria dois novos conceitos: "mais-repressão" (o controle adicional acima do indispensável à existência da sociedade humana civilizada requerido pela dominação social) e "princípio de desempenho" (a forma histórica predominante do princípio de realidade), historicizando o que, segundo Freud, era constituinte da natureza humana. Embora em nenhum momento do livro o nome de Marx seja mencionado, ${ }^{14}$ há uma evidente analogia entre o conceito de mais-repressão e o de mais-valia, assim como o conceito de princípio de desempenho está ligado à crítica marxista do capitalismo e do trabalho alienado.

Assim sendo, numa sociedade em que o trabalho manual é crescentemente substituído por máquinas, Eros pode libertar-se, a energia pulsional antes canalizada para o trabalho pode dirigir-se para outros fins. Entretanto, precisamente porque não há mais base objetiva para a ideologia do trabalho penoso e para a repressão das pulsões é que é necessária a repressão das consciências. Mas se as consciências são dominadas, como é possível a emancipação? A idéia básica é que a força libertadora de Eros, que não pode ser totalmente reprimida e que sempre retorna à superfície, faz explodir os quadros da sociedade estabelecida. Habermas, polemizando com Marcuse em relação a esse ponto, diz que ele "tem uma confiança milenarista na dinâmica renovadora das pulsões". ${ }^{15}$

Chegamos assim ao tema, central em Eros e civilização, de uma sociedade do tempo livre. Com a automação, o pouco trabalho que restaria seria

14 A razão para isso deve ser creditada ao macartismo, que durou até o fim da década de 1950. EroS e civilização foi publicado em 1955.

15 J. Habermas, Perfiles Filosófico-Políticos, Madrid, Taurus, 1986, p.292. 
trabalho não alienado, lúdico. Em outras palavras, deixaria de existir o abismo entre trabalhar e jogar/brincar (spielen): o jogar/brincar tem seu fim em si mesmo, não é um meio eficiente para se atingir um fim diferente do próprio meio. Marcuse inspira-se nessa idéia de Schiller (exposta nas Cartas estéticas para a educação da humanidade) com o objetivo de mostrar que numa sociedade socialista o trabalho deixaria de ser um meio para valorizar o capital e visaria a realização das potencialidades e a satisfação das carências humanas. Em outras palavras, a abolição do trabalho alienado permitiria investir a libido no trabalho - que se tornaria assim trabalho lúdico - e nas relações sociais, o que transformaria a vida num jogo estético/erótico em que os sentidos humanos não seriam moldados pela forma mercadoria. Numa sociedade sem repressão das pulsões a gratificação erótica seria inerente a toda a vida social e ocorreria a reconciliação entre os seres humanos e a natureza, a qual deixaria de ser mera matéria que o homem pode explorar a seu bel prazer (donde o interesse de Marcuse pela ecologia).

Esta é a tese de Eros e civilização. Entretanto, no Prefácio Político escrito em 1966 para uma nova edição do livro reconhece que na sociedade atual não se pode chegar a esse mundo reconciliado. Esse Prefácio faz parte do período "pessimista" da obra de Marcuse que se iniciou em 1964 com O homem unidimensional. Neste livro, que paradoxalmente encontrou grande repercussão no movimento estudantil dos anos 1960, Marcuse vê o capitalismo avançado como uma sociedade "democrática totalitária", em que todo e qualquer tipo de oposição se encontra integrado. Os ousiders, marginais, minorias rebeldes etc. indicariam a existência de uma frágil alternativa, mas também aí não haveria qualquer garantia. ${ }^{16}$

Voltemos porém ao tema antes mencionado do fim do trabalho alienado. Numa entrevista de 1972, diz num tom mais comedido em relação à utopia construída em Eros e civilização:

Enquanto não se puder pensar na possibilidade de uma produção totalmente automatizada, permanecerá sempre um grande resto de trabalho que não pode ser transformado em trabalho criativo. Mas esse trabalho pode ser reduzido de tal forma, que a quantidade se transforma em qualidade, quer dizer, esse resto de trabalho alienado deixará de determinar a existência humana no seu todo. (GR, p.114)

A idéia é que o tempo livre e não mais o tempo de trabalho passaria a ser o elemento organizador da vida social. ${ }^{17} \mathrm{Na}$ verdade, o que está aqui em

16 O homem unidimensional foi avaliado na época de forma muito unilateral, sendo visto como uma ruptura com o marxismo e sem qualquer veleidade política por parte do autor. No meu entender essa interpretação é inteiramente equivocada, o que infelizmente não pode ser demonstrado aqui.

17 Marcuse distingue tempo livre e lazer: o primeiro pode ser associado ao ócio criativo dos antigos, o segundo é o lazer administrado do capitalismo avançado. 
jogo é uma concepção totalmente diferente da vida e da sociedade, uma outra idéia de civilização, distinta da corrente dominante da civilização ocidental, centrada na idéia de progresso como desenvolvimento contínuo e ilimitado das forças produtivas. Ou como diz Marcuse no Prefácio Político de 1966, é necessária "uma inversão no rumo do progresso", "um novo ponto de partida". ${ }^{18}$

Visando desenvolver com um mínimo de precisão o que Marcuse tem em mente quando pensa numa sociedade emancipada, retomemos uma passagem de uma conversa com Habermas (entre outros), em julho de 1977 quando, ao referir-se ao movimento estudantil, diz:

Foi o primeiro movimento que voltou a pensar a revolução socialista como uma diferença qualitativa e a construção do socialismo como uma sociedade qualitativamente diferente, longe do fetichismo das forças produtivas. Nos países capitalistas avançados as forças produtivas se desenvolveram numa extensão mais que suficiente, se é que não se desenvolveram demais. Do que se tratava [na época da rebelião estudantil], e do que continua se tratando, é de um novo princípio de realidade. Isto não é tematizado por Marx; aparece como um traço, sobretudo nos escritos de juventude, mas depois desaparece. ${ }^{19}$

Vejamos com mais cuidado três idéias deste trecho.

1. A revolução socialista (tal como pensada pelos estudantes) tinha por objetivo uma sociedade qualitativamente diferente, distante do fetichismo das forças produtivas. Marcuse questiona aqui a idéia quantitativa de progresso, cujo objetivo é a produtividade vista como algo bom em si mesmo, sem se perguntar para que fim serve o progresso material (econômico, técnico, científico, etc.). Segundo Marcuse a racionalidade tecnológica tem, no capitalismo, um vínculo indissolúvel com a dominação política ou, em outros termos, a ciência e a técnica estão inseridas num "projeto" que serve aos interesses do capital, elas não são neutras. ${ }^{20}$

No projeto socialista de Marcuse, não se trata de aproveitar o aparato tecno-científico do capitalismo, como se este fosse despido de valores sociais e morais e como se a idéia de desenvolvimento das forças produtivas pudesse continuar a ser utilizada, desde que as forças produtivas estivessem a serviço de novos objetivos. É isto, mas isto não é tudo. Este é o ele-

18 Herbert Marcuse, Eros e civilização, Rio de Janeiro, Zahar Editores, 1978, p.15. Doravante, EC.

19 J. Habermas, op. cit., p.280.

20 A crítica de Marcuse antecipa a do Grupo Krisis ao irracionalismo da "racionalidade" empresarial: como seu objetivo é o lucro, pouco importa que a natureza e a sociedade sejam aniquiladas. Après moi, le déluge! é o lema adequado aos amigos da "modernização"capitalista (ver Grupo Krisis, Manifesto contra o trabalho, São Paulo, Conrad Livros, 2003). 
mento marxista do seu pensamento, mas ele vai mais longe: Marcuse é um precursor das atuais preocupações ecológicas ao questionar a idéia de desenvolvimento econômico como simples crescimento, que leva a uma relação destrutiva com a natureza. Donde a dúvida mais que justificada expressa na citação acima, se não seria necessário limitar o desenvolvimento das forças produtivas, frear a corrida impetuosa do progresso em direção (quem sabe?) à destruição da própria humanidade. O que ele exprime no Prefácio Político de 1966 da seguinte maneira:

Ao passo que as revoluções anteriores acarretaram um desenvolvimento mais amplo e mais racional das forças produtivas, nas sociedades superdesenvolvidas de hoje, porém, revolução significaria a inversão dessa tendência: eliminação do superdesenvolvimento e de sua racionalidade repressiva. (EC, p.18)

Contudo, criticar o progresso não significa rejeitar a técnica e retornar à vida selvagem e sim pensar numa nova técnica e numa nova ciência, voltadas para a "pacificação da existência". Ainda o Prefácio Político:

A rejeição da produtividade afluente, longe de constituir um compromisso com a pureza, a simplicidade e a 'natureza', poderia ser um indício (e uma arma) de um estágio superior de desenvolvimento humano, baseado nas realizações da sociedade tecnológica. Sendo interrompida a produção de bens supérfluos e destrutivos (um estágio que significaria o fim do capitalismo em todas as suas formas) - as mutilações somáticas e mentais infligidas ao homem por essa produção seriam eliminadas. (EC, p.18)

No socialismo a natureza deixaria de ser objeto de dominação dos homens. Estes passariam a ter com ela uma relação fraterna, de colaboração, e não de destruição. Numa sociedade que não fosse regida pela supremacia do capital sobre a sociedade e que tivesse outros valores que não a eficiência, a produtividade, a competitividade, a vida seria um fim em si mesma e não um meio para a valorização do capital, seria uma vida "pacificada".

Questionar a noção corrente de progresso, como faz Marcuse (e o grupo Krisis, que rejeita a civilização do automóvel, p. ex.), significa levantar a bandeira da mudança radical das necessidades humanas.

2. A segunda idéia em que devemos nos deter é a de "novo princípio de realidade". O que isto significa? Marcuse utiliza esse conceito de Freud, definindo-o "como a soma total daquelas normas e valores que supostamente governam o comportamento normal numa sociedade estabelecida" (GR, p.144). No capitalismo, as normas/valores que governam a sociedade estão evidentemente ligadas ao princípio em torno do qual tudo gira - o lucro. As necessidades dos indivíduos, que eles consideram como genuinamente 
suas, são na verdade impostas pelos interesses do capital, sobretudo a necessidade de consumir o supérfluo.

Marcuse reconhece que a distinção entre falsas e verdadeiras necessidades, embora problemática, é fundamental para se pensar a sociedade socialista. Numa entrevista de novembro de 1972, começando por identificar as "falsas necessidades", diz:

A distinção entre necessidades verdadeiras e falsas é uma das mais difíceis e naturalmente não pode ser verificada "cientificamente". Antes de mais nada, a distinção é válida negativamente, na medida em que se pode mostrar que os homens contraíram necessidades que são prejudiciais, que retardam um maior desenvolvimento humano, que retardam a emancipação dos homens, quando não os tornam impossíveis por um largo período. Delas faz parte, por exemplo, - e aqui evidentemente falo apenas dos países industriais altamente desenvolvidos, a situação é essencialmente diferente no Terceiro Mundo - a necessidade, que já se tornou imperiosa, de, a cada ano, ou a cada dois anos comprar um carro novo, ou a necessidade de comprar um aparelho de televisão maior ou mais sofisticado, a necessidade de ficar sentado durante horas na frente desse aparelho de televisão, a necessidade de comprar todas as mercadorias que hoje são vistas como símbolos de status. São necessidades negativas, que satisfazem de fato uma necessidade que se tornou real, mas ao satisfazê-la retardam a emancipação do homem do trabalho alienado, de todo o sistema de valores do capitalismo e trabalham contra essa emancipação. (GR, p.112-3)

A crítica à sociedade de consumo, um tema sempre retomado por Marcuse, é nesta época de exacerbamento da "estética da mercadoria" mais atual que nas décadas de 1960/70, quando mesmo nos meios urbanos ainda existiam dimensões da vida não dominadas pelo valor de troca - todos nós ainda passamos a infância e a juventude num mundo "caipira" de pouco consumo em comparação com a atual lavagem cerebral mercadológica a que somos submetidos diariamente.

Logo a seguir, tentando formular a idéia de "necessidades verdadeiras" em termos positivos, diz Marcuse:

o único juízo de valor, por assim dizer, pressuposto numa análise crítica consiste em que é melhor para os homens viver que morrer, e que é melhor viver bem que viver mal. Acredito que hoje, e não apenas hoje, se pode definir de maneira bastante precisa o que se chama uma vida melhor, ou seja, que isso não significa apenas criar e satisfazer necessidades materiais e também culturais sempre maiores, mas realmente viver de uma maneira essencialmente diferente: isso significa não continuar fazendo do corpo um instrumento de trabalho alienado, não continuar fazendo seu caminho na sociedade e através da sociedade de uma maneira essencialmente destrutiva, deixar de ter as características agressivas da sociedade capitalista - mas justamente levar uma vida livre de todo esse negativo, e na verdade porque, na minha opinião, nos encontramos numa situação nova e excepcional, em que as neces- 
sidades materiais e também as necessidades culturais básicas da maioria da população foram satisfeitas. Revela-se assim que o trabalho social é crescentemente utilizado nos chamados objetos e necessidades de luxo, as quais não fazem parte da subsistência humana ou, para falar como Marx, que o capitalismo cada vez mais se reproduz por meio do trabalho improdutivo. Dito positivamente: alcançamos na história o estágio em que o trabalho alienado socialmente necessário não precisa mais ser trabalho full-time, mas pode ser reduzido a um mínimo, dando lugar aos poucos a um trabalho mais ou menos criativo e a um tempo livre mais ou menos autônomo. (GR, p.113-4)

Aqui, em primeiro lugar, o que chama a atenção é o tema da sociedade afluente - as necessidades materiais e culturais da maioria da população foram satisfeitas, por isso não há oposição. E hoje que vivemos em um patamar de desigualdade nunca visto desde o fim da Segunda Guerra Mundial? Será que ficou mais próxima a possibilidade de uma oposição crescente à idéia de que o mundo é uma mercadoria e de que a suprema felicidade na vida consiste no acesso às mercadorias?

Em segundo lugar, retornamos ao tema anterior de uma sociedade fundada no tempo livre. A idéia é que numa sociedade em que tivesse sido eliminado o trabalho alienado, o tempo livre seria controlado autonomamente pelos indivíduos, e não seria o "hedonismo enfurecido de idiotas do consumo" (Robert Kurz) que presenciamos hoje. ${ }^{21}$

3. E finalmente, a última idéia do trecho citado é a de que uma sociedade socialista qualitativamente diferente, fundada num novo princípio de realidade, não aparece em Marx, ou melhor, aparece no jovem Marx dos Manuscritos econômico-filosóficos de 1844, mas depois desaparece. Este texto do jovem Marx, como já foi mencionado, teve para Marcuse uma importância que não podemos negligenciar. Assim que foi publicado em 1932, Marcuse escreveu um longo ensaio intitulado "Novas fontes para a fundamentação do materialismo histórico" em que dava uma guinada em relação à sua anterior forma de pensar, muito influenciada por Heidegger, porque via nessas idéias do jovem Marx os fundamentos de uma revolução radical, ou seja, uma revolução dos sentidos, da sensibilidade humana. Para Marcuse, a "verdadeira" libertação humana implica a "emancipação dos sentidos", o fim da "sublimação repressiva". O socialismo seria criado por um "novo tipo de homem", ${ }^{22}$ entendido como "novo ser sensível" (guiado pela "razão sensível"), que reconstruiria o mundo "de acordo com as leis da beleza" (donde a relação fraterna com a natureza) e não segundo a lógica da

21 Também neste aspecto é possível fazer um paralelo entre a crítica de Marcuse e a do grupo Krisis à sociedade de consumo.

22 Citações tiradas de Herbert Marcuse, Contra-revolução e revolta, Rio de Janeiro, Zahar, 1981, p.67. 
valorização do capital. O sentido geral desta apropriação do jovem Marx é claro: a rejeição por parte de Marcuse do "socialismo realmente existente".

Vejamos por fim, para concluir, um trecho de um artigo intitulado "Teoria e prática" ${ }^{23}$ de 1974, escrito para comemorar os 50 anos do Instituto de Pesquisa Social, em que Marcuse aponta as contradições do capitalismo avançado ("neocapitalismo") - o que faz com que a teoria marxista continue atual.

No que consistiriam essas contradições do capitalismo que levam à possibilidade da ruptura? Escreve o nosso filósofo:

A saturação do mercado nas metrópoles e a necessidade de uma acumulação crescente forçam o neocapitalismo a produzir em ampla escala mercadorias e serviços que representam 'produtos de luxo', indo além das necessidades vitais, materiais ou culturais, mas nem por isso a pobreza e a miséria são reduzidas fora das camadas sociais privilegiadas capazes de comprar esses produtos. Mas isso significa que na escala da sociedade, o tempo de trabalho necessário à reprodução da força de trabalho diminui cada vez mais (ilusão de liberdade) sem que diminua a quantidade total do trabalho assalariado: este continua ocupando todo o tempo, continua o conteúdo mesmo da vida. É cada vez mais difícil abafar a tomada de consciência de que uma parte do tempo consagrada ao trabalho é inútil, é desperdício (produtiva e necessária apenas para o modo capitalista de produção): ela alimenta a necessidade de um 'reino da liberdade' que no mundo neocapitalista da mercadoria é constantemente produzida e constantemente negada. (p.74)

Como bom marxista que fez a lição de casa, Marcuse afirma que o capitalismo para se desenvolver precisa continuar acumulando. Com esse fim, deve continuar produzindo produtos supérfluos, uma vez que as necessidades vitais já teriam sido satisfeitas, pelo menos nos países ricos. Mas, apesar disso, a desigualdade social não é eliminada, nem sequer nesses países. E se está dada a possibilidade de eliminar a carência material (pois de fato ainda não foi eliminada, a não ser para as camadas privilegiadas da sociedade), isso significa que está também aberta a possibilidade de diminuir a jornada de trabalho necessária para reproduzir a força de trabalho. Contudo, observa Marcuse, o tempo de trabalho não diminuiu. ${ }^{24}$ Finalmente pensa que em virtude dessa situação objetiva (em que não é mais preciso trabalhar tanto) aumenta a consciência de que o tempo dedicado ao trabalho é inútil, ou seja, aumenta a consciência de que ele só é necessário

23 Théorie et pratique, in Herbert Marcuse, Actuels, Paris, Editions Galilée, 1976.

24 Ricardo Antunes, em Os sentidos do trabalho - ensaio sobre a afirmação e a negação do trabalho, São Paulo, Boitempo, 1999, mostra que nos anos 90 aumentou a jornada de trabalho na Inglaterra, o que em princípio só confirmaria o diagnóstico que Marcuse fez no início dos anos 1970. 
à reprodução do sistema capitalista e, conseqüentemente, abrir-se-ia uma brecha no sistema.

Hoje algo mudou em relação ao diagnóstico de Marcuse. Se na sua época a automação crescente permitia vislumbrar, pelo menos em termos teóricos, o fim do trabalho alienado e a possibilidade de uma mudança civilizatória, hoje essa possibilidade teórica permanece, mas um complicador foi acrescido à conjuntura: o desemprego. Embora no Prefácio Político de 1966 diga que "Uma progressiva redução da mão de obra pare[ça] ser inevitável, e o sistema, para fazer face a essa eventualidade, te[nha] de prover à criação de ocupações sem trabalho (...)"( EC, p.21) - o desemprego se anuncia - Marcuse via essa mudança de maneira otimista, pensando que ela indicava a tendência de nos libertarmos do domínio da mercadoria. Mas hoje, quando a predominância do capital sobre a sociedade não é questionada a não ser pela esquerda radical que não tem força política, a utopia marcuseana parece menos enraizada na realidade. Como lutar por uma cultura do tempo livre, do ócio (luta que não se separa do combate ao capitalismo) quando todos pedimos para sermos explorados por algum patrão que queira nos empregar?

Além disso, vivemos uma situação paradoxal: o progresso técnico, em vez de libertar os seres humanos, só intensificou a submissão ao trabalho daqueles que ainda têm uma ocupação remunerada. ${ }^{25} \mathrm{~A}$ fim de manter a competitividade e os lucros, as empresas capitalistas intensificaram os ritmos de produção em todos os níveis, diminuíram o número de trabalhadores, etc. o que leva à superexploração dos que têm a sorte de manterem o emprego. Esse modelo produtivista acabou sendo exportado para outras instituições, como por exemplo, as universidades, onde seus profissionais sofrem com uma sobrecarga de tarefas inimaginável há anos atrás. Dada essa situação desumana sob todos os aspectos parece-me que a análise de Marcuse do capitalismo tardio e as alternativas que propõe fazem mais sentido do que nunca. A crítica da civilização fundada na ética do trabalho, da eficiência, da produtividade, do progresso contínuo das forças produtivas valores que só serviram até agora para destruir a natureza produzindo cada vez mais riqueza para um número cada vez menor de pessoas - torna Marcuse precursor de toda uma literatura atual centrada na crítica do trabalho abstrato $^{26}$ e, por conseguinte, do capitalismo. Diferentemente da recepção enviesada dos anos 1960/70, que enxergava nele exclusivamente o guru da contra-cultura, hoje vemos claramente que Marcuse foi, antes de mais

25 Numa entrevista dada em 1979, Marcuse reconhece essa situação (GR, p.15-16).

26 Viviane Forrester, O horror econômico, São Paulo, Editora UNESP, 1997, os já citados Manifesto contra o trabalho e Os sentidos do trabalho. 
nada, um filósofo marxista politicamente engajado. Tanto que numa entrevista à $\mathrm{BBC}$, em 1978, diz:

A teoria marxista será refutada quando o conflito entre a nossa riqueza social crescente e seu uso destrutivo for resolvido no interior do capitalismo; quando o envenenamento do meio ambiente for eliminado; quando o capital puder se expandir de maneira pacífica; quando o abismo entre ricos e pobres for continuamente reduzido; quando o progresso técnico for criado para servir o crescimento da liberdade humana - e tudo isso, repito, no interior do capitalismo. ${ }^{27}$

Talvez a clara filiação de Marcuse ao marxismo e o engajamento político daí decorrente sejam o motivo real do pouco caso com que sua obra foi tratada nas duas últimas décadas do século XX. Afinal uma época de "contra-revolução preventiva", para retomarmos uma fórmula do próprio filósofo no início dos anos 1970, não só não pode ver com bons olhos, como também considera ultrapassado um pensamento que se opõe ao primado da mercadoria, à dominação sem sentido, à irracionalidade e à manipulação das consciências. A mudança de ares que começa a se anunciar o traz de volta, mas desta vez pondo-o no lugar que lhe pertence - como um dos pensadores que criou e desenvolveu a Teoria Crítica da sociedade sem nunca excluir um de seus elementos fundamentais: a defesa da transformação radical da sociedade.

LOUREIRO, I. Herbert Marcuse - anticapitalism and emancipation. Trans/Form/ Ação, (São Paulo), v.28(2), 2005, p.7-20.

- ABSTRACT: Marcuse had in Brazil, in the 70s, an one-sided reception, being seen only as a guru of the counter-culture. Against this misconception the paper exposes the intrinsic relationship between theory and practice in Marcuses's philosophy, characterized as a political philosophy whose main concern is the radical transformation of capitalist society.

- KEYWORDS: Herbert Marcuse, Critical Theory, western civilization, revolution.

27 B. Magee, Men of ideas, Londres, BBC, 1978, p.71. 